\title{
The Fracture Properties of Injection Molding PCIABS Blend
}

\author{
Ming-Hsiung $\mathrm{Ho}^{1, \mathrm{a}}$, Pin-Ning Wang ${ }^{2, \mathrm{~b}}$ and Jung-Peng Yeh ${ }^{1, \mathrm{c}}$ \\ ${ }^{1}$ Department of Mechanical Engineering, Taoyuan Innovation Institute of Technology, Jhongli, 32091, \\ Taiwan, R.O.C. \\ ${ }^{2}$ Department of Material and Fiber, Taoyuan Innovation Institute of Technology, Jhongli, 32091, \\ Taiwan, R.O.C. \\ amorrisho@tiit.edu.tw, bpnwang@tiit.edu.tw, cyjp@tiit.edu.tw
}

\begin{abstract}
Keywords: PC/ABS, Blend, Injection Molding Condition, Fracture Toughness, Skin layer
Abstract. PC/ABS blend has widely used in vehicle industry. In this dissertation, fracture toughness of PC/ABS blend was studied. The specimens were prepared under various injections molding conditions, such as filling time, melting temperature and mold temperature. The fracture mechanisms were examined with a scanning electron microscopy. The following conclusions can be drawn from the tests. The best injection molding condition of fracture toughness specimen was filling time 2 seconds, melting temperature $260^{\circ} \mathrm{C}$ and mold temperature $55^{\circ} \mathrm{C}$. The fracture toughness is varied with according with skin layer normalized thickness. The stress-whiten, splits and fibril-like surfaces were typical fracture mechanisms.
\end{abstract}

\section{Introduction}

$\mathrm{PC} / \mathrm{ABS}$ is product of amorphous, thermoplastic polymer blends on the basis of polycarbonate (PC) and Acrylonitrile-Butadiene-Styrene (ABS). PC/ABS combines the excellent properties of the two materials, ABS formability and PC material mechanical, impact strength, heat resistance, and resistance to weather ultraviolet (UV) properties. The material usually used in household, electrical, electronic automotive interior, exterior parts, precision machine parts and food industry etc. For parts forming methods, the injection molding method has excellent surface accuracy, short processing cycle, low cost, and can be used to molding complex shapes.

The fracture toughness research in plastic is still quite limited, because of the complex structure of the plastic material and the varied fatigue characteristics. To make plastic materials such as metal materials widely used in industry and vehicle industry, the material fatigue properties must have systematic study and discussion.

$\mathrm{Lu}$ [1] studied elastic-plastic fracture toughness of a PC/ABS blend by the conventional J-integral and the crack tip opening displacement (CTOD) methods. Abuzar [2] has been investigated fracture behavior of ABS polymeric material under the full range of in-plane loading conditions using a new loading device to obtain more reliable results. Li [3] experimentally investigated the mixed-mode fracture of PC/ABS alloy. The appearance, growth, and coalescence of crazes can be observed in the micro-fracture processes, and the macro-crack propagation direction is finally determined by the coalesced direction of crazes. Lee [4] found that addition of PC could have toughened recycled PMMA matrix under impact test conditions. Seidler [5] studied the toughness behavior of PC/ABS blends under dynamical loading $\left(1 \mathrm{~ms}^{-1}\right)$ based on the $J$-integral concept. It was shown that the materials exhibit very different toughness behavior depending on temperature and ABS content.

Because PC/ABS blend is processed and formed by some factors, it needs to find out suitable conditions for its applications.

In this study, the investigative object of PC/ABS material was using injection molding method for forming a test specimen and following ASTM E399 standard to explore the material propertied under different filling time, melt temperature, mold temperature. It was evaluated that the PC/ABS plastic material propertied with molding conditions and low cycle fatigue testing conditions. After the experiment, the specimen fracture surfaces were examined with the scanning electron microscope, in order to understand the related fracture mechanism. 


\section{Methods}

Material. The material used in this study is the GE (General Electric) produces granular PC/ABS plastic. The material brand name is Cycoloy-C1110HF. The volume percentage of containing the PC and the ABS is $60 \%$ and $40 \%$, and the average density is $1.13 \mathrm{~g} / \mathrm{cm} 3$.

Specimen preparation. The injection mold layout is shown in Fig. 1. The test specimens used in experiments are melting glue injection from the tail end.

The molding conditions were filling time set to $2 / 6 / 12 / 14$ seconds, melt temperature designed for $200 / 220 / 240 / 260 / 280{ }^{\circ} \mathrm{C}$ and mold temperature was set to $35 / 50 / 65 / 80{ }^{\circ} \mathrm{C}$. The specimen number and the detailed conditions of the injection molding are listed in Table 1.

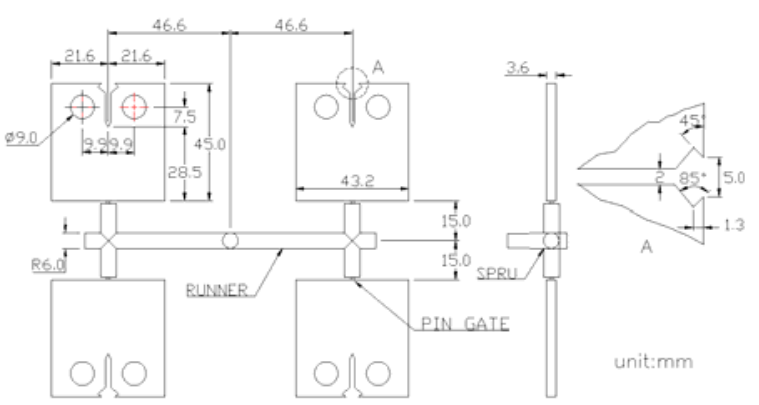

Figure 1. The layout in injection mold.

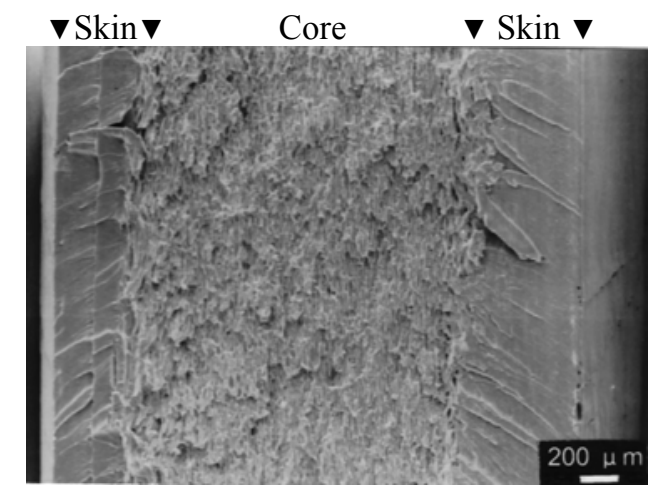

Figure 3. The fracture surface of skin and core layers of M280.

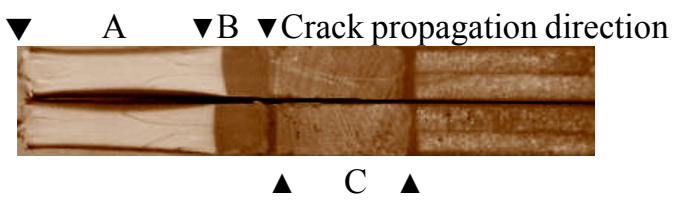

Figure 2. The stress whiten in damage area.

Table 1. Specimens forming conditions.

\begin{tabular}{|c|c|c|c|}
\hline Number & $\begin{array}{c}\text { Filling } \\
\text { time } \\
(\mathrm{s})\end{array}$ & $\begin{array}{c}\text { Melting } \\
\text { temperatur } \\
\mathrm{e} \\
\left({ }^{\circ} \mathrm{C}\right)\end{array}$ & $\begin{array}{c}\text { Mold } \\
\text { Temperatu } \\
\text { re } \\
\left({ }^{\circ} \mathrm{C}\right)\end{array}$ \\
\hline $\mathrm{T} 2$ & 2 & 260 & 80 \\
\hline $\mathrm{T} 6$ & 6 & 260 & 80 \\
\hline $\mathrm{T} 12$ & 12 & 260 & 80 \\
\hline $\mathrm{T} 14$ & 14 & 260 & 80 \\
\hline $\mathrm{M} 200$ & 2 & 200 & 80 \\
\hline $\mathrm{M} 220$ & 2 & 220 & 80 \\
\hline $\mathrm{M} 240$ & 2 & 240 & 80 \\
\hline $\mathrm{M} 260$ & 2 & 260 & 80 \\
\hline $\mathrm{M} 280$ & 2 & 280 & 80 \\
\hline $\mathrm{C} 35$ & 2 & 260 & 35 \\
\hline $\mathrm{C} 50$ & 2 & 260 & 50 \\
\hline $\mathrm{C} 65$ & 2 & 260 & 65 \\
\hline $\mathrm{C} 80$ & 2 & 260 & 80 \\
\hline
\end{tabular}

During the injection molding, the material was preheated at $110^{\circ} \mathrm{C}$ for $4-6$ hours to get rid of the moisture before it can be used in an injection molding machine. The specimens were cooled to room temperature in atmosphere, after the specimens being ejected out of the mold.

Fracture toughness test. The Experiment planning and methods were followed ASTM E399 standard. Because of the test piece initial crack length a, in accordance with specifications should be between $0.45 \mathrm{~W}$ to $0.55 \mathrm{~W}$ (W= $36 \mathrm{~mm}$ is specimen width). The total length of cracks in this test is to take $\mathrm{a}=18 \mathrm{~mm}$, in which the injection molding crack is $7.5 \mathrm{~mm}$. The crack length from $7.5 \mathrm{~mm}$ to $16 \mathrm{~mm}$ was produced by mechanical processing methods. The last $2 \mathrm{~mm}$ is by fatigue pre-crack method. The specimens were test by MTS $810100 \mathrm{kN}$ servo-hydraulic testing machine. The PC/ABS specimens with different molding conditions after pre-crack were tensile loading till specimen broke. After the test, specimen fracture surface was observed by a scanning electron microscope (SEM). The load-crack opening displacement data was recording. The load and displacement data on the slope of 
the linear range to take five percent deviation obtained material load $\mathrm{PQ}$, and calculate the fracture toughness $\mathrm{K}_{\mathrm{c}}$ of the material, the relationship is:

$$
\begin{aligned}
& K_{c}=\frac{\mathrm{P}_{\mathrm{Q}}}{\mathrm{BW}^{1 / 2}} \mathrm{f}\left(\frac{a}{W}\right) \\
& f\left(\frac{a}{W}\right)=\frac{\left[2+\left(\frac{a}{W}\right)\right]\left[0.886+4.64\left(\frac{a}{W}\right)-13.32\left(\frac{a}{W}\right)^{2}+14.72\left(\frac{a}{W}\right)^{3}-5.6\left(\frac{a}{W}\right)^{4}\right]}{\left[1-\left(\frac{a}{W}\right)\right]^{3 / 2}}
\end{aligned}
$$

\section{Results and discussions}

Normalization thickness. As showed in fig. 2, in the pre-crack and pull off surface after the test, the test specimens had whitening phenomenon at fracture surface. This is a stress whiten phenomenon. The phenomenon are also happened in pure PPO, HIPS, PPO/HIPS blend materials. Moloney [6] had explained the phenomenon: Because skin molecule along a direction perpendicular to the tension direction, when the force to make the epidermis molecular forward direction pull in the same direction, causing whitening phenomenon. The color of layer is changed because the molecule orientation re-arrange after external force applied. After force applied process, the surface layer has a lower density and a lower light reflectivity than the original material. A is damage area, B is pre-cark area, $\mathrm{C}$ is machining crack area.

The SEM microstructure of compact tension (CT) test specimen in thickness direction which is perpendicular to the molecular orientation is showed in Fig. 3.

Fig. $4 \sim 6$ are the skin layer normalized thickness distribution under different injection mold conditions in the vertical compact tension specimen thickness direction. The figures are showed that the material's maximum skin layer normalized thicknesses are in mold temperature of $35^{\circ} \mathrm{C}$, melt temperature of $200{ }^{\circ} \mathrm{C}$ and the filling time of 2 seconds. The maximum skin layer normalized thickness is decrease downward as the filling time, melt temperature and mold temperature increase.

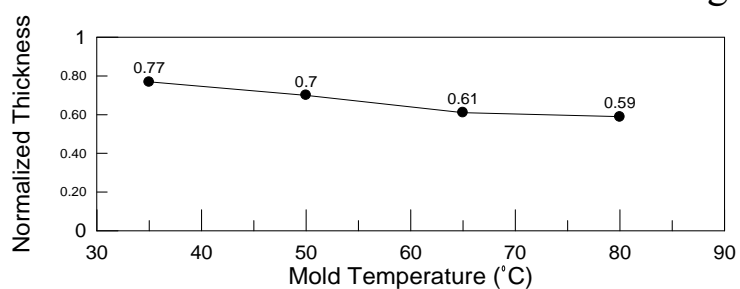

Figure 4. Mold temperature and skin layer normalized thickness.

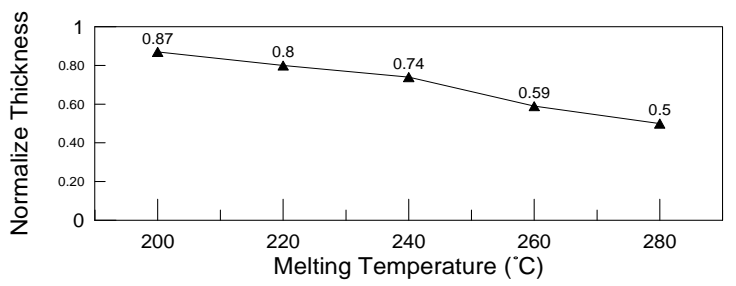

Figure 5. Melt temperature and skin layer

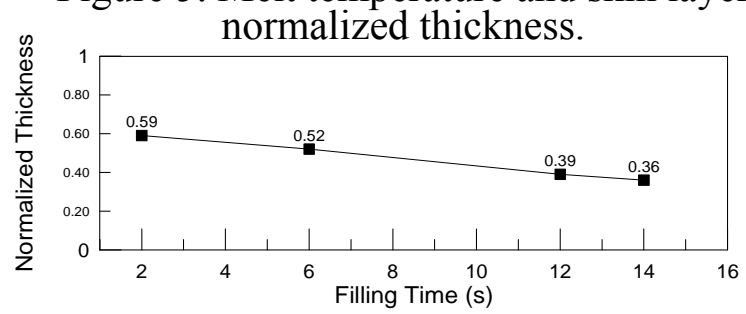

Figure 6. Filling time and skin layer normalized thickness

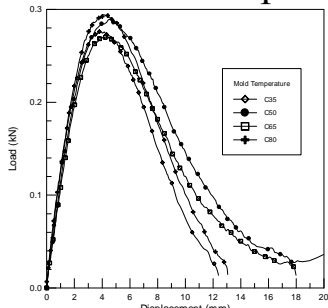

Figure 7. The load-crack open displacement curves under mold temperature conditions.

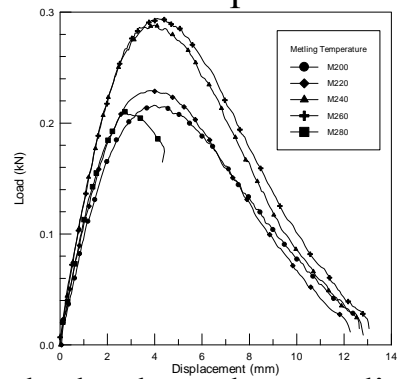

Figure 8 . The load-crack open displacement curves under melting temperature conditions.

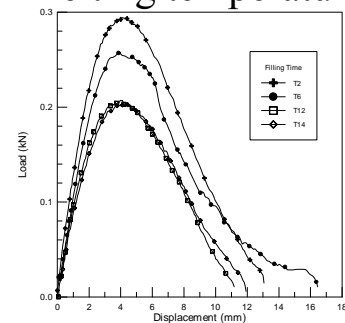

Figure 9. The load - crack open displacement curves under filling time conditions. 


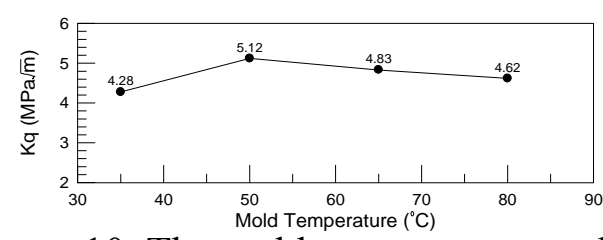

Figure 10. The mold temperature conditions.

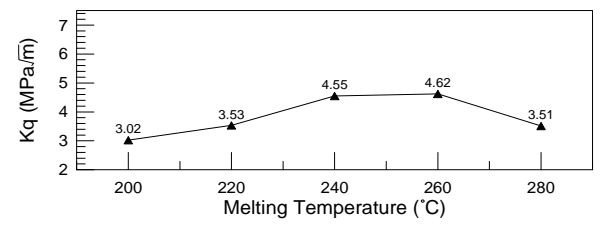

Figure 11. The melt temperature conditions.

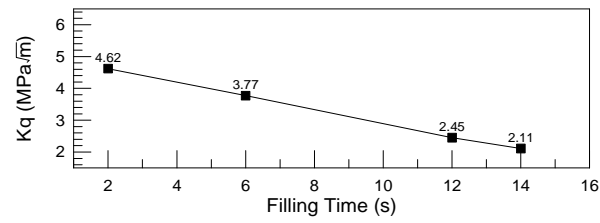

Figure 12. The filling time conditions.

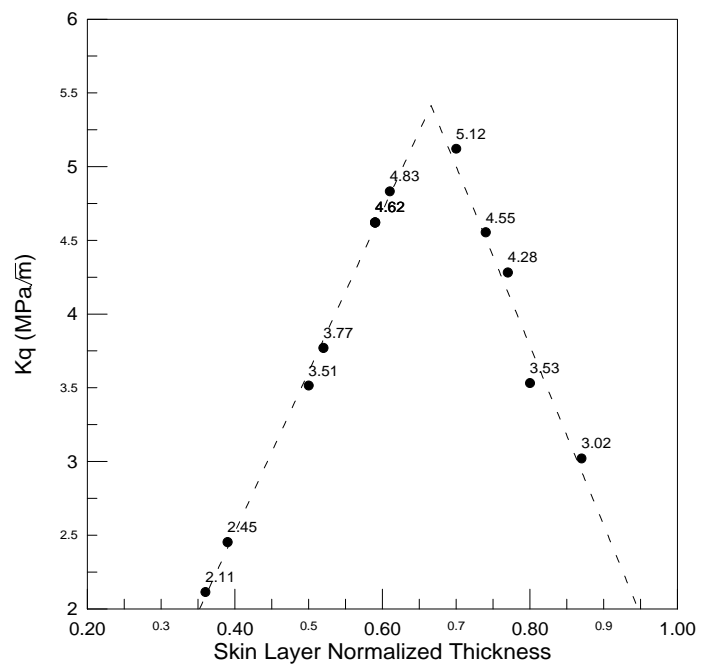

Figure 13. The relation between $\mathrm{Kq}$ and skin layer normalized thickness.

Fracture toughness. The Fig. $7 \sim 9$ show that the load and crack open displacement curves belong to TYPE I as shown in E399, the load that is by 5\% deviation slope method to determined P5 and to locate $\mathrm{P}_{\max }$.

From Fig. 10, the mold temperature had little effect on the $\mathrm{Kq}$, the difference between the maximum and minimum value is only $0.84 \mathrm{MPa} \sqrt{\mathrm{m}}$, when compared to melt temperature and filling time conditions, the difference value is small.

And overall $\mathrm{Kq}$ values at mold temperature conditions are higher than other molding conditions. Although D80 (M260, T2) in mold temperature conditions is order 3, but in the melt temperature and filling time conditions have maximum $\mathrm{Kq}$ value.

Effect of melting temperature from Fig. 8 and Fig. 11 observed, the $\mathrm{K}_{\mathrm{q}}$ gradually increased from M200 to a maximum value M260, but M280 namely drop. In Fig. 12, under filling time conditions, the time increases, and the $\mathrm{K}_{\mathrm{q}}$ values decline. The $\mathrm{K}_{\mathrm{q}}$ value of $\mathrm{T} 12$ and $\mathrm{T} 14$ is the smallest. It is showed that too long fill time did not help for the fracture toughness. Fig. 13 shows the relationship between normalization skin layer thickness and fracture toughness. The data could be divided into two linear regression lines, the two lines intersection point of the normalized thickness is 0.67 and the value of fracture is $5.41 \mathrm{MPa} / \mathrm{m}$. From the point, the optimum injection molding conditions will be filling time 2 seconds, melt temperature $260^{\circ} \mathrm{C}$ and mold temperature of $55^{\circ} \mathrm{C}$.

When the skin layer normalized thickness is less than 0.67 and fracture toughness relationship would be $\mathrm{Kq}=-1.83+$ (skin layer normalized thickness) $* 10.88$.

The skin layer normalization thickness greater than 0.67 , and the fracture toughness relationship would be $\mathrm{K}_{\mathrm{q}}=13.51+$ (skin layer normalized thickness) * (-12.16)

Fracture mechanisms. From the Fig. 2 and 3, the main failure mechanism with a pre-split and pull off during the test, the specimen notched end and crack edges have stress whitening phenomenon. The specimen fatigue pre-crack area with pull-off area of the fracture surface microscopic observations, showing: cracks in the front end of the pre-split region into a laminated sheet-like intermediate core layer of soft material.

\section{Conclusions}

The results, process conditions of this chapter for a comprehensive PC/ABS plastic material fracture toughness can be summarized as follows: 
1. The destruction of compact tension toughness test specimens from the surface to the center of the fiber orientation can be divided into two regions, the epidermis molecular forward parallel to the direction of flow of melt glue. The central part of the core layer molecular forward perpendicular to the direction of flow of melt glue.

2. The relation between skin layer normalized thickness and fracture toughness $\mathrm{Kq}$ has a critical value is skin layer normalized thickness 0.67 and fracture is $5.41 \mathrm{MPa} \sqrt{\mathrm{m}}$.

3. For this optimum value estimates from Fig. 13, the injection molding conditions for filling time 2 seconds, melt temperature $260^{\circ} \mathrm{C}$, mold temperature of $55^{\circ} \mathrm{C}$.

4. In skin layer area, the surface is like a sheet of brittle fracturing. The core section has pull out fiber; it shows the core layer molecular orientation is perpendicular to the cross section.

\section{Acknowledgements}

In this paper, the research was sponsored by the National Science Council (Project No. MOST 103-2221-E-253-009)

\section{References}

[1] M.L. Lu: Poly. Vol. 37 (1996), p. 4289

[2] E.O. Abuzar: Poly. Eng. and Sci. Vol. 54 (2014), p 2086

[3] H. Li: J. Mech. Sci. and Tech. Vol. 29 (2015), p. 33

[4] S.K. Lee: Inter. Poly. Pro. Vol. 27(2012), p. 626

[5] Seidler S., W. Grellmann: J. of Mat. Sci. Vol. 28, (1993), p. 4078

[6] A.C. Moloney: Fractography and Failure mechanisms of Polymers and Composites. Elsevier Science Publishers Ltd (1989). 